\title{
EFFECT OF BASIC PRETREATMENT ON SACCHARIFICATION OF WATER HYACINTH
}

\author{
Hari Narayanan T $\mathbf{R}^{\mathbf{1}}$, Sathvik Varma $\mathbf{V}^{\mathbf{2}}$, Jagadish $\mathbf{H}$ Patil ${ }^{\mathbf{3}}$ \\ ${ }^{1,2}$ Student, ${ }^{3}$ Assistant Professor, Department of Chemical Engineering, R.V. College of Engineering, Karnataka, India, \\ harinarayanantr.1902@gmail.com, sathvikvarma14@gmail.com,patil_rvcechemical@rediffmail.com
}

\begin{abstract}
The world has seen a vast expansion in industrialization and this has in turn seen an increase in demand for fossil fuels. To sustain such a pace of development, these fuels are being consumed at a rapid rate. This dependence on the fuels coupled with their rapid rate of depletion has called for research to look for alternative fuels. Biofuels like bio-ethanol and bio-diesel are being considered as replacements. Bio-ethanol is being given special consideration, as it can be used as a substitute to, or as a blend with petrol in existing gasoline engines, without much modifications being made to these engines. The substrates under consideration are that of the biomass genre, and Water Hyacinth being of special importance.. Water Hyacinth is an aquatic weed which grows in most tropical parts of the world. It has considerably lower lignin and higher cellulosic content, which makes it a suitable substrate for bio-ethanol production. The three main steps for bio-ethanol production are pretreatment, which makes the biomass amenable to further treatment, Saccharification, the process by which complex sugars are broken down to simple reducing sugars and fermentation, where the sugars are fermented by the action of relevant fungi. This study focusses on the Saccharification step of the process, specifically focusing on the effect of pretreatment on the Saccharification of Water Hyacinth. Three samples of powdered Water Hyacinth, along with 3 samples of Base pretreated Water Hyacinth powder were subjected to the Saccharification process using TrichodermaViride. It was observed that the Saccharification yields for the pretreated samples were in excess of 200\% greater than that of the Saccharification yields of the powdered Water Hyacinth samples without pretreatment. These results were observed on the day 2 of the process. The results of this study will be taken into consideration for the fermentation step of the process.
\end{abstract}

Keywords: Water Hyacinth, Pretreatment, Saccharification, Reducing sugar yield, High yields.

\section{INTRODUCTION}

The progressive expansion of civilization and the related everdeveloping science and technology present us with many new problems. It is primarily a question of energy, food and the pollution of our natural environment. The shortage of liquid fuels is more than predictable [1].The use of conventional fuels as primary energy source has led to scarcity in fuel, climate change, environmental degradation and human health problems [2].The global oil availability is practically fixed because the natural formation of petroleum is a process which takes a very long time and it is not replaced at the rate at which it is being extracted [3].

With these adverse effects being noticed and an impending energy crisis, studies onBio-fuels are important because they replace petroleum fuels. A number of environmental and economic benefits are claimed for bio-fuels [4]. Lignocellulose is considered as an attractiveraw material for the production of fuel ethanol, because of its availability in large quantities at low cost [5]. The efficient utilization of the hemicellulose component of lingo cellulosic feed stocks $(25 \%$ of dry weight of hardwood) offers an opportunity to reduce the cost of fuel ethanol production by $25 \%$ [6].
Lignocellulosic materials are found in almost any kind of waste, and the challenge is to efficiently utilize this biomass component in the process of producing fuel ethanol from it. Fuel ethanol is also produced in some cases, from specially gown feed stocks like corn. These are generally called bioenergy crops.

The attributes of a bio-energy crop are as follows [7]:

- Naturally grown vegetation, grows perennially.

- High cellulose and low lignin content per unit volume of dry matter.

- Easily digestible

Water Hyacinth (WH) is a widely prevalent aquatic weed in India. Its high content of hemicellulose $(30-55 \%$ of dry weight) can provide hemicellulosic sugars for bio- conversion to ethanol [8]. The lower lignin content in water hyacinth as compared to other biomass used for the conversion process is an important parameter to be considered. The conversion of Water Hyacinth to ethanol is achieved in three major steps namely, pretreatment of the raw material, saccharification of complex sugar molecules to simple sugars and finally fermentation of the produced simple sugars into bioethanol 
[9]. The first step, called Pretreatment, is the process where cellulosic biomass is made amenable to the action of enzymes [10]. The second step is Saccharification, in which the complex carbohydrates present in Cellulose and Hemicellulose are broken down to simple sugars. This is done by exposing the substrate to Saccharification micro-organisms like TrichodermaViride or Aspergilus Niger. The final step of the process in anaerobic fermentation, where fungi such as Saccharomyces Cerevisiae act upon the reducing sugars in the absence of Oxygen to form ethanol

The first step, namely pretreatment is a very important step and this study aims to prove the importance of pretreatment experimentally. Within the context of production of fuels from biomass, pretreatment has come to denote processes by which cellulosic biomass is made amenable to the action of hydrolytic enzymes. All naturally occurring, and most refined, cellulosic materials require pretreatment to become accessible to the enzymes that mediate hydrolysis. The need for pretreatment is emphasised by the fact that typically, hydrolysis yields in the absence of pretreatment are less than $20 \%$ of theoretical yields, whereas yields after pretreatment often exceed $90 \%$ of theoretical [8]. In naturally occurring cellulosic materials, cellulose is closely associated with hemicellulose and other structural polysaccharides, and carbohydrate-rich microfibrils are surrounded by a lignin seal. A primary function of pretreatment is to open up this multicomponent-matrix so that it becomes accessible [8]. The structure of a typical biomass is as given below in Fig 1.

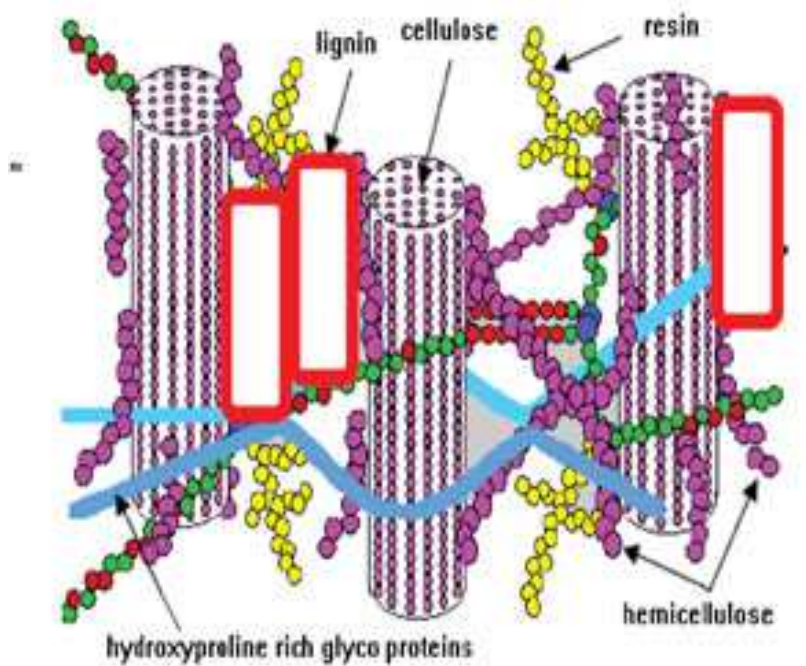

Fig1: Typical structure of biomass

The figure illustrates the working of the pretreatment methods in successfully breaking the multicomponent matrix to free the Cellulose and Hemicellulose [11]

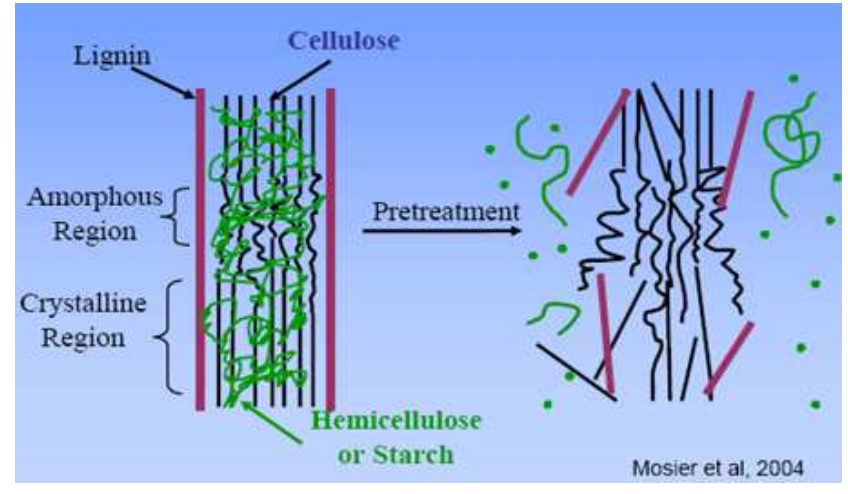

Fig 2: Mechanism of Pretreatment

A large number of methods of pretreatment are used, but some of the most common methods are mechanical communition followed of acid or base treatment. This step breaks the aforementioned matrix and makes the cellulosic content amenable to the Saccharification micro-organisms.

The second step of the process is the Saccharification step. The final yield of this step is a good amount of reducing sugars, which can be fermented in the fermentation step. Typical Saccharification microorganisms are TrichodermaViride, Trichoderma Reesei, Aspergilus Niger, Aspergilus Awamori etc. This is then followed by the fermentation step where the reducing sugar is fermented to form ethanol.

This study aims to show experimentally, the effectiveness of base pretreatment on the Saccharification of powdered Water Hyacinth Substrate. The Saccharification micro-organism used was TrichodermaViride (MTCC-1)

\section{MATERIALS AND METHODS}

\subsection{Collection and Drying of Water Hyacinth}

Water Hyacinth was taken from Kengeri Lake, Bangalore and the leaves were separated from the stalk and kept aside. One half of the leaves and the stalks were dried separately in sunlight for a period of 72 hours. These leaves and stalks were then dried in a vacuum oven, at a temperature of $80^{\circ} \mathrm{C}$ for a period of 5 hours.

\subsection{Primary Pretreatment Process}

The dried stalks and leaves were then powdered in a blender, so as to obtain a uniform, free flowing powder. This was taken as the substrate for Saccharification process.

\subsection{Base Pretreatment Process}

The other half of the Water Hyacinth leaves and stalks were soaked in $\mathrm{NaOH}$ solution $(0.1 \mathrm{~N})$ for a period of 48 hours. The leaves and stalks were then sun dried for a period of 72 hours. 
They were then subjected to drying in a vacuum oven, at a temperature of $80^{\circ} \mathrm{C}$, for a period of 5 hours. The dried leaves and stalks were subjected to mechanical communition in a blender. The free flowing powder obtained was taken as a substrate for the Saccharification process.

\section{4 pH Test for Substrates}

The $\mathrm{pH}$ of the two substrates, namely, substrate without pretreatment, and base pretreated substrate were measured. For this process, $1 \mathrm{~g}$ of the substrate was added to $25 \mathrm{ml}$ of distilled water and $\mathrm{pH}$ was measured using a $\mathrm{pH}$ meter. The results are shown in table 1.

Table 1: $\mathrm{pH}$ test results

\begin{tabular}{|l|l|}
\hline $\begin{array}{l}\text { Type of } \\
\text { pretreatment }\end{array}$ & $\mathrm{pH}$ \\
\hline Base pretreated & 6.07 \\
\hline $\begin{array}{l}\text { Without chemical } \\
\text { pretreatment }\end{array}$ & 4.92 \\
\hline
\end{tabular}

\subsection{Preparation of Media}

The media used was called Modified Mendell's media was used for the Saccharification process. The media consisted of the following components:

- Urea $(0.3 \mathrm{~g} / \mathrm{l})$

- Potassium di-hydrogen phosphate $(2.0 \mathrm{~g} / \mathrm{l})$

- Ammonium sulphate $(1.4 \mathrm{~g} / \mathrm{l})$

- Peptone $(0.75 \mathrm{~g} / \mathrm{l})$

- Calcium chloride $(0.3 \mathrm{~g} / \mathrm{l})$

- Magnesium chloride $(0.3 \mathrm{~g} / \mathrm{l})$

- Yeast extract $(0.25 \mathrm{~g} / \mathrm{l})$

A solution was prepared by adding the components in one liter of water. The contents of the solution were stirred to ensure uniformity. $100 \mathrm{ml}$ of the prepared media was then added to 9 flasks.

\subsection{Nomenclature of Flasks and Addition of}

\section{Substrates}

Nine $250 \mathrm{~mL}$ Erlenmeyer Flasks were used in the experiment. Each flask was filled with $100 \mathrm{ml}$ of modified Mendell's media. Three flasks were maintained as control (labeled "TC1, T-C2, T-C3") to which substrate was not added. The six other flasks were labeled based on the type of pretreatment used for the respective water hyacinth sample, namely, "T-B" for base pretreated substrate and "T-N" for the sample without any chemical pretreatment(neutral). The flasks were then sealed tight with cotton plugs and were then autoclaved at 25 psi for 2 hours. The nomenclature of the flasks is described in table 2.
Table 2: Nomenclature of flasks containing media and substrate

\begin{tabular}{|l|l|}
\hline Flask Name & Contents \\
\hline T-C1, T-C2. T-C3 & Media (100mL in each) \\
\hline T-B1, T-B2, T-B3 & $\begin{array}{l}\text { Media (100mL) and Base } \\
\text { pretreated substrate (1g) in } \\
\text { each }\end{array}$ \\
\hline T-N1, T-N2, T-N3 & $\begin{array}{l}\text { Media (100mL) and substrate } \\
\text { without chemical } \\
\text { pretreatment (1g) in each }\end{array}$ \\
\hline
\end{tabular}

\subsection{Addition of TrichodermaViride Inoculum}

The flasks were taken out of the autoclave and kept aside till the contents attained room temperature. The flasks were then taken to a Laminar AirFlow (LAF). The flasks were then inoculated with TrichodermaViride spores, obtained from a petri plate culture. The flasks were plugged and kept aside for the fungus to grow and the Saccharification process to initiate.

\subsection{DNS Test}

A micropipette was calibrated for $1.5 \mathrm{~mL}$ and it was then used to pipette out the contents from each flask. The contents were transferred to a correspondingly labeled centrifuge tubes. The tubes were centrifuged for 15 minutes at $2000 \mathrm{rpm}$. The micro pipette was calibrated for $0.75 \mathrm{ml}$, and supernatant liquid from each tube was pipetted out and transferred to correspondingly labeled test tubes. $3 \mathrm{ml}$ of Di Nitro Salicylic Acid(DNS) reagent was added to each of the test tubes. The test tubes were heated in a water bath for 10 minutes till there was a visible change in the colour of the contents of the test tubes. The control solution was used to calibrate the colorimeter used for the measurement of optical densities (OD) of the different samples.

\subsection{Test for Reducing Sugars}

The DNS test is used to measure the amount of reducing sugars produced in the saccharification process. This process involves measuring the optical density of the test tube contents using a colorimeter. Higher the optical density values, higher the quantity of reducing sugars produced. This is governed by the Beer-Lambert law.

The test was conducted at an interval of 24 hours starting from the day after inoculation. The tests were carried out over a continuous 5- day period and the results are depicted in Table 3 and 4.The OD values of the different samples were determined at $540 \mathrm{~nm}$. A standard calibration curve was prepared to estimate the reducing sugar content thus obtained. This is depicted in Figure 3. 
The corresponding OD values were used to calculate the quantity of reducing sugar in the solution using the curve. The obtained values were noted in table 5 .

Table 3: OD values of the individual samples on different days.

\begin{tabular}{|l|l|l|l|l|l|l|}
\hline \multirow{2}{*}{ Day } & \multicolumn{3}{|l|}{ Base Pretreated } & \multicolumn{3}{l|}{ Without Pretreatment } \\
\cline { 2 - 7 } & T-B1 & T-B2 & T-B3 & T-N1 & T-N2 & T-N3 \\
\hline Day 1 & 0.02 & 0.02 & 0.02 & 0.02 & - & 0.01 \\
\hline Day 2 & 0.10 & 0.09 & 0.10 & 0.03 & 0.03 & 0.03 \\
\hline Day 3 & 0.08 & 0.08 & - & 0.03 & - & 0.02 \\
\hline Day 4 & 0.07 & - & 0.06 & 0.02 & 0.02 & 0.02 \\
\hline Day 5 & 0.06 & 0.05 & 0.06 & 0.01 & 0.02 & - \\
\hline
\end{tabular}

Table 4: Consolidated table for OD values of different samples.

\begin{tabular}{|l|l|l|}
\hline Day & Base Pretreated & Without Pretreatment \\
\hline Day 1 & 0.02 & 0.015 \\
\hline Day 2 & 0.10 & 0.3 \\
\hline Day 3 & 0.08 & 0.025 \\
\hline Day 4 & 0.065 & 0.02 \\
\hline Day 5 & 0.06 & 0.015 \\
\hline
\end{tabular}

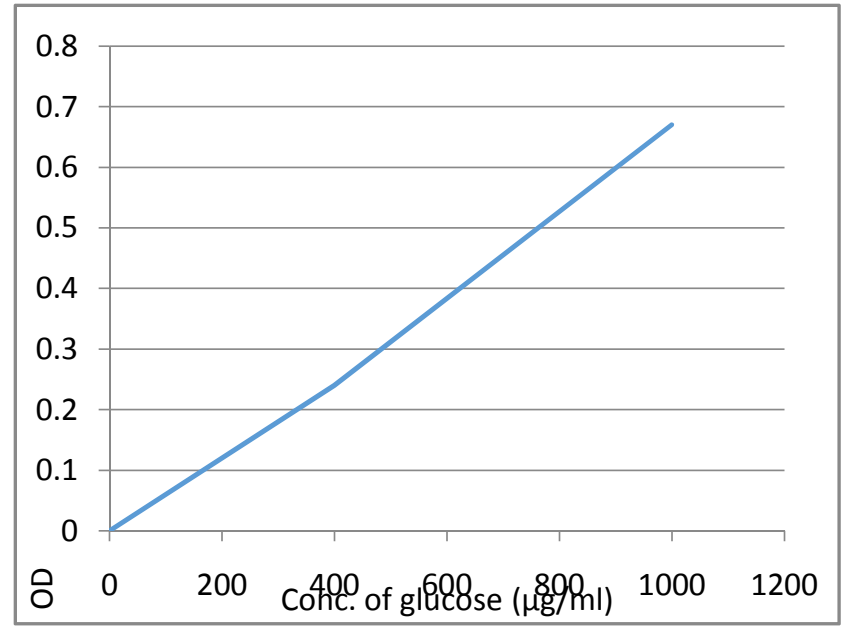

Fig 3: Standard Calibration curve

Table 5: Reducing sugar yield for different samples

\begin{tabular}{|l|l|l|}
\hline Day & $\begin{array}{l}\text { Reducing sugar } \\
\text { yield for Base } \\
\text { Pretreated }(\mu \mathrm{g} / \mathrm{mL})\end{array}$ & $\begin{array}{l}\text { Reducing sugar yield } \\
\text { for } \\
\text { Pretreatment }(\mu \mathrm{g} / \mathrm{mL})\end{array}$ \\
\hline Day 1 & 20 & 15 \\
\hline Day 2 & 100 & 30 \\
\hline Day 3 & 80 & 25 \\
\hline Day 4 & 65 & 20 \\
\hline Day 5 & 60 & 15 \\
\hline
\end{tabular}

\section{RESULTS AND DISCUSSION}

The results were in accordance to the previous work published by the authors and it is seen that the optimum yield of reducing sugars is obtained on the second day after pretreatment.The results also show that the yield of reducing sugars from the base pretreated samples exceed that obtained from the non-pretreated sample in excess of three times.This was found to be $180 \mu \mathrm{g} / \mathrm{mL}$ for the base pretreated sample and $30 \mu \mathrm{g} / \mathrm{mL}$ for the non-pretreated sample. The comparative yield is shown in Figure 4.

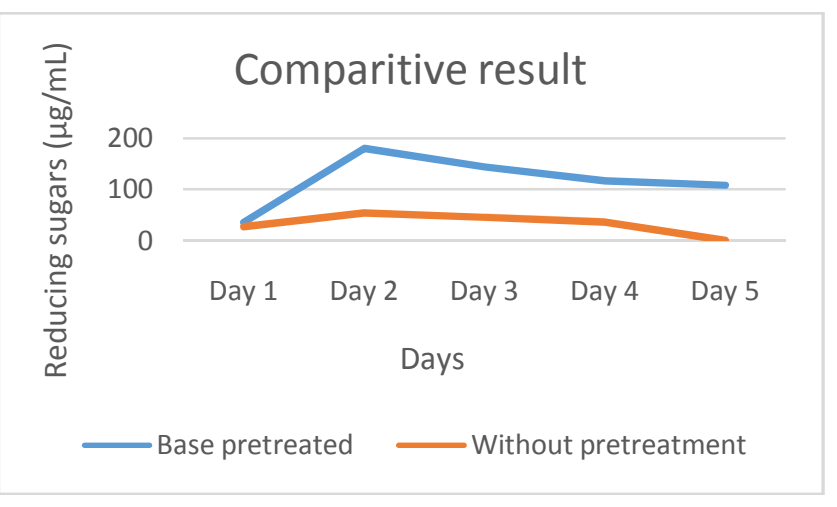

Fig4: Graph showing the yields of base pretreated and nonpretreated substrates.

\section{CONCLUSIONS}

From the experimental data obtained, we can conclude that pretreatment is a vital step in the process of bio ethanol synthesis from Water Hyacinth. The pretreatment process with base significantly helps in the de-lignification of the water hyacinth substrate. This is important because lignin is a major obstacle to the accessibility of the cellulosic and hemicellulosic components of water hyacinth substrate, which are important for the production of reducing sugars. We can conclude that without pretreatment, the synthesis of reducing sugars is in negligible quantities, which ultimately deems the process not viable.

\section{FUTURE PROSPECTS}

The results from this experiment will be incorporated in the second part of the conversion process, i.e, fermentation of the reducing sugars to ethanol. Other prospects include changes in $\mathrm{pH}$ of the substrate to determine the optimum $\mathrm{pH}$ for the saccharification process, use of other microorganisms for saccharification, such as Trichoderma Reesei or Aspergilus Niger, and studying the effect of agitation on the results, etc.

\section{ACKNOWLEDGEMENTS}

Firstly, we acknowledge that we could not have performed this experiment without the help of our group-mates, Kamala $\mathrm{K}$ and Shivashankar B. We would like to thank Dr H.G. Ashok 
Kumar, Head of Biotechnology department, RVCE, for his guidance. We would also like to thank MrArmugam for his invaluable assistance in the laboratory

\section{REFERENCES}

[1] JanuszSzczodrak and Jan Fiedurek, "Technology for conversion of Lignocellulosic biomass to Ethanol", Biomass and Bioenergy Vol. 10, Nos 5/6, pp. 367-375 (1996).

[2] Patil J.H, MolayanLourdu Antony Raj, Bhagyashree, Vantimar Dinesh and Rohith, "Kinetic Modeling of Anaerobic Co-digestion of Water Hyacinth and Poultry Litter", Research Journal of Chemical Sciences, Vol 3(6), 69-73,(2013)

[3] SathvikVarma V, Hari Narayanan T R, Kamala K, Shivashankar B, "Comparison of Acidic and Basic Pretreat*ment on Saccharification of Water Hyacinth", Int. Journal of Innovative research in science, engg. and technology, Vol 2(9), 4804-4812, (2013).

[4] Mustafa Balat and HavvaBalat, "Recent trends in global production and utilization of bio-ethanol fuel", Journal of Applied Energy, No 86, 2273-2282, (2009).

[5] Lynd, L.R, "Production of ethanol from lignocellulosic materials using thermophilic bacteria: critical evaluation of potential and review.", Adv. Biochem. Eng./Biotechnol. 38, 1-52, (1989)

[6] Hinman, N.D., Wright, J.D., Hoagland, W., Wyman, C.E., "Xylose fermentation, an economic analysis.", Appl. Biochem. Biotechnol. 20/21, 391-401. (1989)

[7] Anjanabha Bhattacharya and Pawan Kumar, "Water hyacinth as a potential biofuel crop", Electronic Journal of Environmental, Agricultural and food chemistry, ISSN 1579-4377, (2010).

[8] J.N. Nigam, "Bioconversion of water-hyacinth (Eichhornia crassipes) hemicellulose acid hydrolysate to motor fuel ethanol by xylose-fermenting yeast", Journal of Biotechnology 97, 107-116, (2002).

[9] Lynd L.R," Overview and evaluation of Fuel ethanol from cellulosic Biomass", Annual Review of Energy and the Environment., 21:403-65, (1996).

[10] Rangarajan Hari Narayanan, VarmaSathvik V, Krishnappa Kamala, BasavarajShivashankar, Patil J H, Determination optimum period of Saccharification of water hyacinth using TrichodermaReesei and Aspergilus Niger", Research Journal of Chemical Sciences., Vol 3(8), 49-52, (2013).

[11] Mosier et all. "Biofuel Beyond corn", Purdue Agriculture, (2004). 